\title{
A Study on the Suitable Slat Angle of Blinds in Different Seasons
}

\author{
Zhou $\mathrm{Li}^{1}{ }^{\text {, * }}$ \\ Faculty of Architectural, Civil Engineering and Environment, Ningbo University \\ Ningbo, China \\ Email: 458629028@qq.com
}

Keywords: Blinds; Building energy performance; Daylighting; Solar radiation

\begin{abstract}
Solar shading devices play an important role in reducing cooling energy consumption and glare risk. This paper carried out a simulation based analysis on movable solar shading devices. Different blind angles are considered in order to determine the suitable solar shading performance for summer and winter conditions. Results show that the suitable slat angle is 20 degrees for summer conditions while it is 110 degrees for winter conditions. Furthermore, the fitting equations of solar shading performance for different blind dimensions are given in order to help designers select the suitable shading devices for applications.
\end{abstract}

\section{Introduction}

Building energy increases significantly in recent years in China and thus reducing building energy consumption has been considered as a strategy for sustainable development [1]. Solar shading devices play an important role in reducing cooling energy consumption as well as providing glare protection [2-8]. Blind shading is a very common energy saving measures in hot summer and cold winter zone [9]. However, the solar shading performance has not been determined in Ningbo city, a hot summer and cold winter zone city in China, due to the lack of suitable software programs for analyzing movable solar shades (the only building simulation program in this city is PKPM) [10]. Thus this paper tries to solve this problem in order to provide suggestions for designers.

\section{Methodology}

According to the design standard in China, the solar shading coefficient is calculated as follows:

$$
S c=a x^{2}+b x+1
$$

Where $x=A / B, \mathrm{~A}$ and $\mathrm{B}$ is determined according to the Fig. 1. Coefficients of $\mathrm{a}$ and $\mathrm{b}$ are determined according to the following building simulation. 


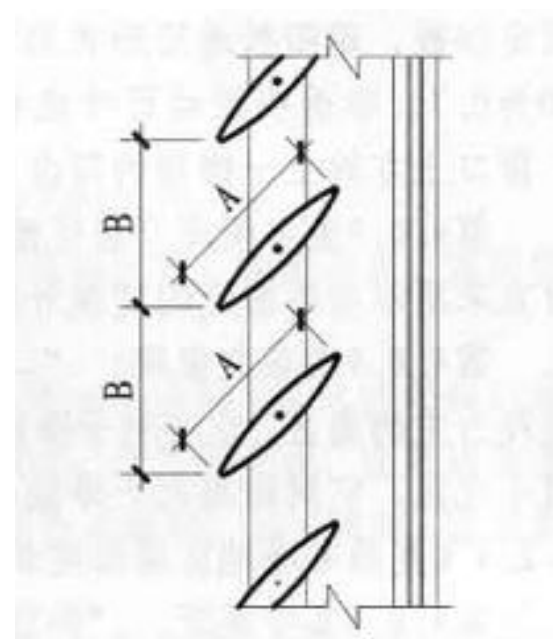

Fig. 1 the dimension of the blind shading

A typical room $(3 \times 3 \times 3 \mathrm{~m})$ was modeled in the simulation software Energyplus [11] to carry out the building performance simulation. The external wall was a $240 \mathrm{~mm}$-brick wall and the other three internal walls, roof and floor were considered as adiabatic. The room temperature is set 26 oC for cooling and $18 \mathrm{oC}$ for heating and the air-conditioners are running throughout the year to meet the indoor temperature setting. The total power density of miscellaneous loads (including lighting systems and occupants) is $4.3 \mathrm{~W} / \mathrm{m} 2$. The slat angle of the blind shading is changed from 10 to 170 degrees with an internal of 10 degrees. The simulation will be used to calculate the SC value by the ratio of the transmitted solar radiation to the total solar radiation and then the coefficients of $a$ and $b$ will be determined for different blind dimensions as shown in Fig. 1.

\section{Results and Discussion}

Fig. 2 shows the transmitted solar radiation in cooling and heating seasons. It can be seen that the least solar transmittance is for the angle of 10 degrees while the largest is for the angle of 110 degrees. The corresponding SC values are calculated and shown in Fig. 3. It can be seen that the lowest SC value is about 0.1 while the highest is about 0.6 . For summer conditions, it is better to use a lowest SC value which reduces the largest solar gains, while it is the opposite situation for winter conditions. However, the slat angle for summer conditions should also take into account the daylighting performance since a low daylight illuminance may harm to indoor occupants. Thus the daylighting simulation should also be taken to determine which angle is suitable for both daylighting and solar protection.

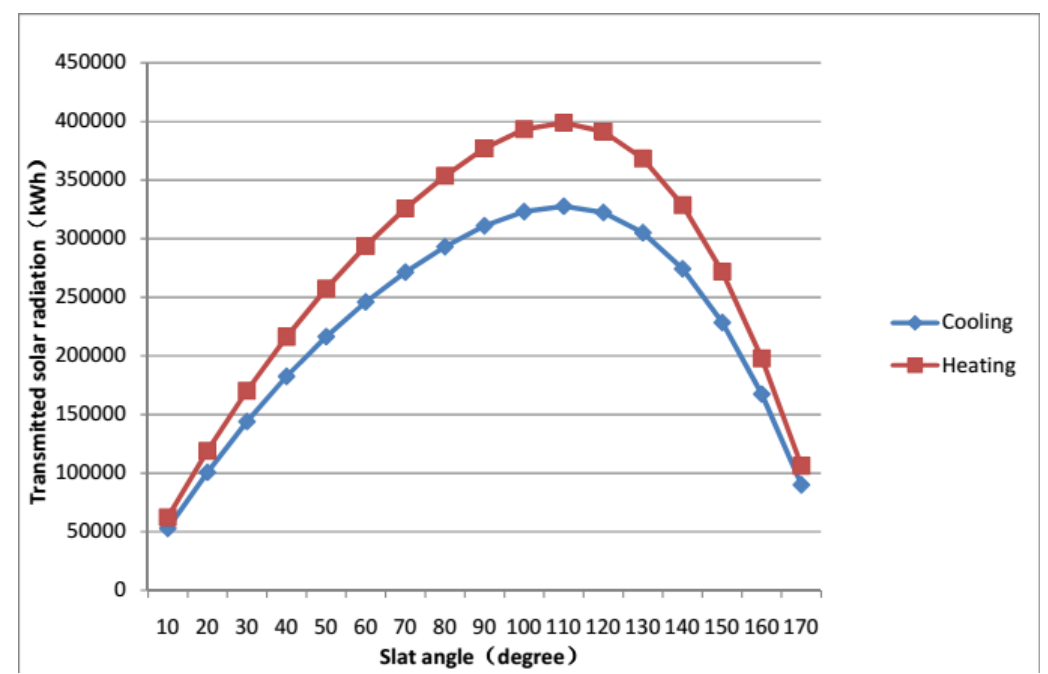

Fig. 2 Relationship between transmitted solar radiation and slat angle 


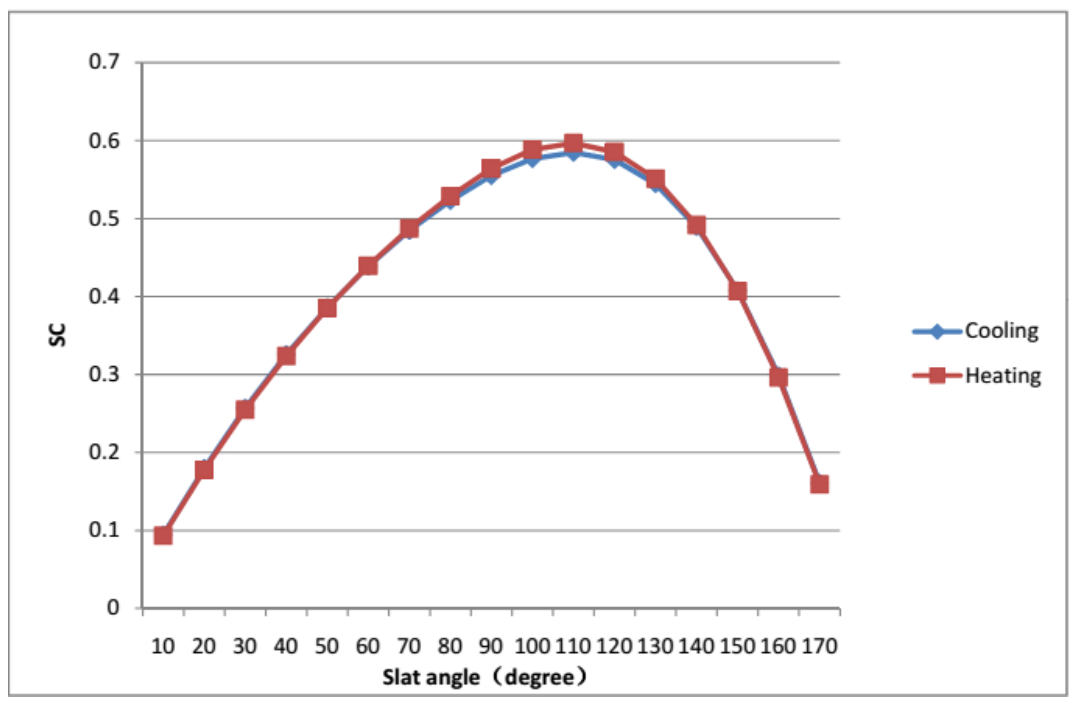

Fig. 3 Relationship between SC values and slat angle

The following Fig. 4 shows the annual daylight illuminance for slat angles of 10 and 20 degrees. It can be seen that the average daylight illuminance for slat angle of 10 degrees is 202lux, while it is $390 l u x$ for the angle 20 degrees. For a comfortable visual condition, the daylight illuminance should be higher than 300lux. Therefore, the slat angle of 20 degrees is suitable for summer conditions and the slat angles of 110 degrees for winter conditions.

According to the above analysis, the $\mathrm{x}$ is changed from 0.1 to 1 for different slat dimensions. The results are shown in Fig. 5 and Fig. 6 and the regression between SC values and $\mathrm{x}$ is also given in the figures. It can be seen that it has a good fitting effect with a $\mathrm{R}$ square higher than 0.99 , indicating that the fitting equations are suitable for determine SC values. Thus coefficients of $\mathrm{a}$ and $\mathrm{b}$ are determined for winter and summer conditions.

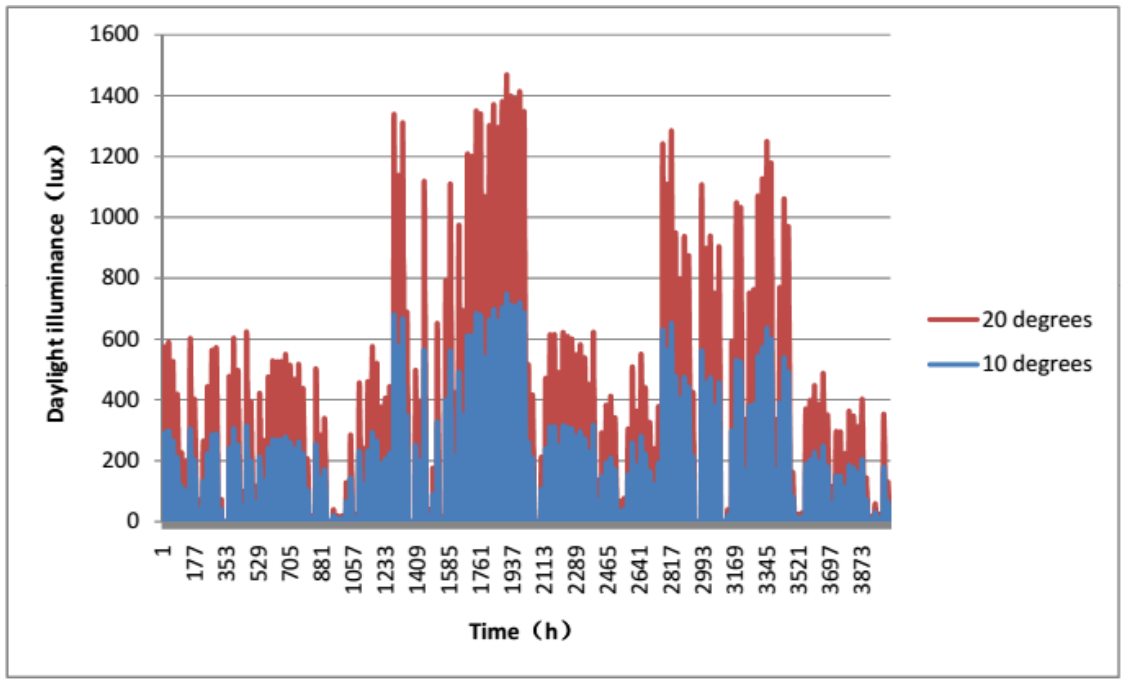

Fig. 4 Daylight illuminance for slat angles of 10 and 20 degrees 


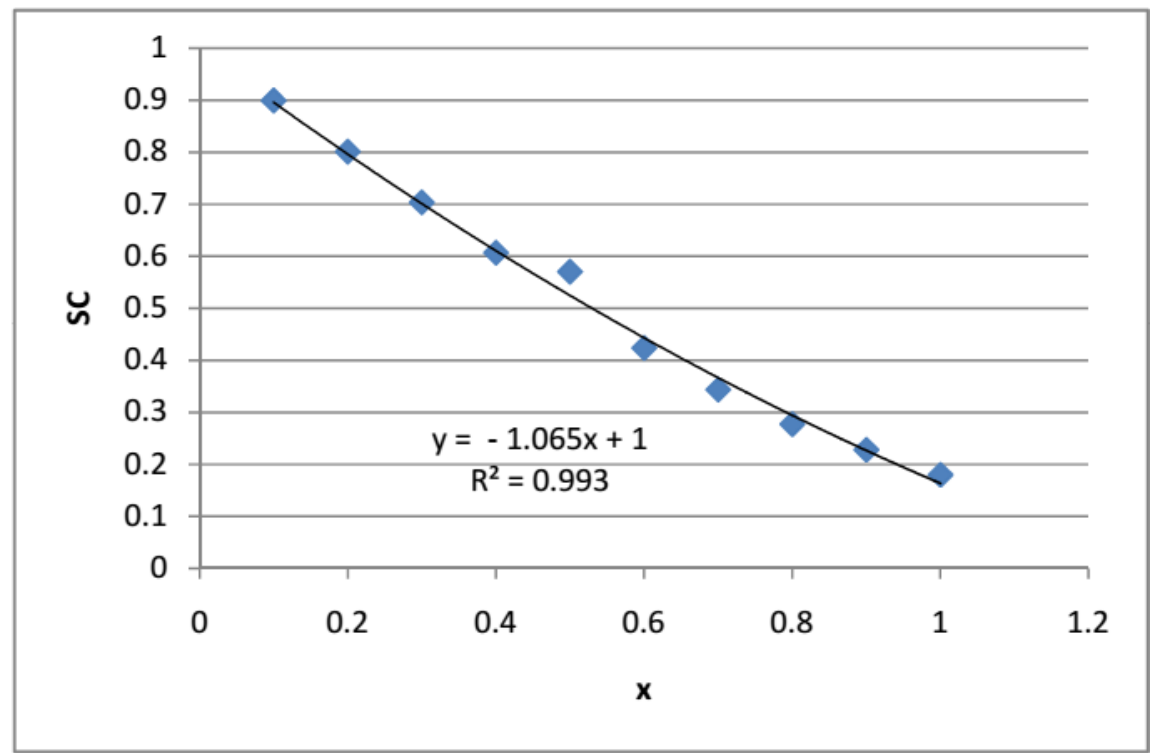

Fig. 5 Relationship between SC values and $\mathrm{x}$ in summer conditions

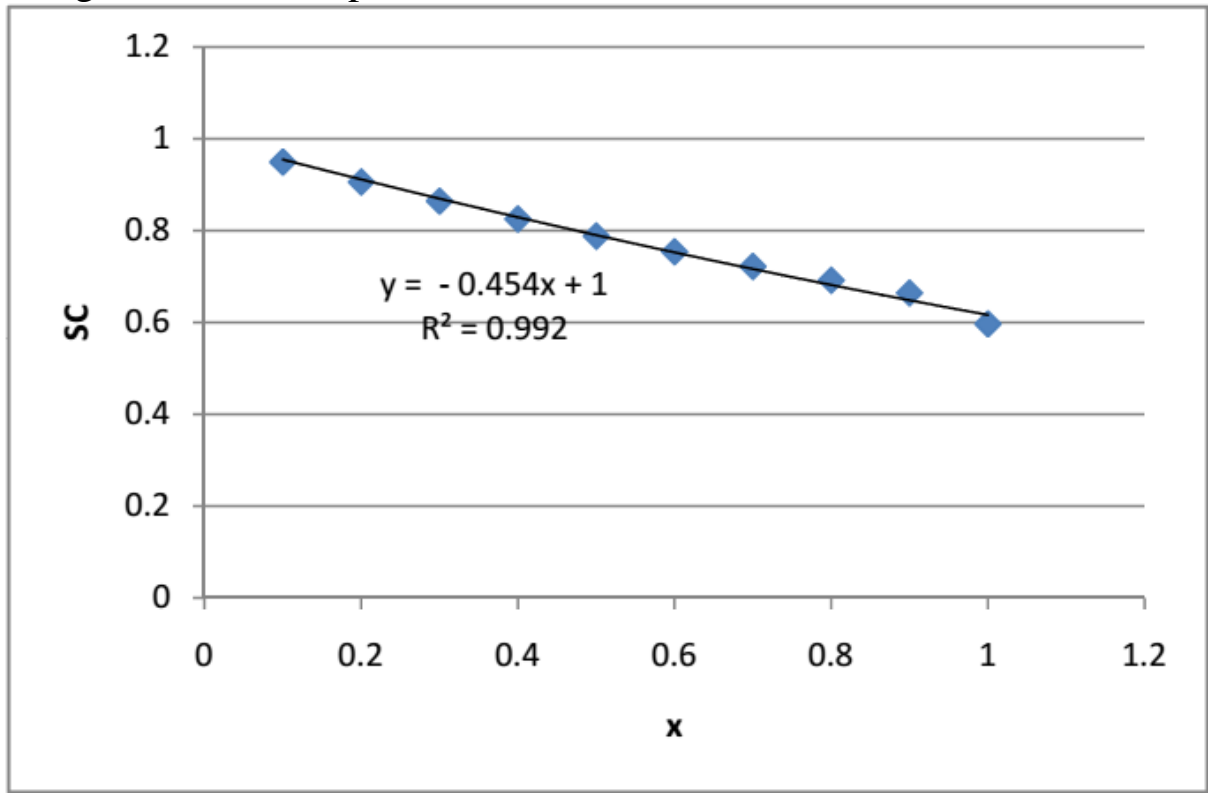

Fig. 6 Relationship between SC values and $\mathrm{x}$ in winter conditions

\section{Conclusions}

This paper carried out a simulation based analysis on movable solar shading devices. Different blind angles are considered in order to determine the suitable angles for summer and winter conditions. Finally, fitting equations for different blind dimensions are given, which help designers select the suitable blinds for application.

\section{Acknowledgement}

This work was supported by the natural science foundation of Zhejiang Province (LQ13E080009) and by K.C.Wong Magna Fund in Ningbo University. The author would like to thank my teacher Dr. Jian Yao for his guidance. 


\section{References}

[1] Yao, J., Energy optimization of building design for different housing units in apartment buildings. Applied Energy, 2012. 94: p. 330-337.

[2] Yao, J., An investigation into the impact of movable solar shades on energy, indoor thermal and visual comfort improvements. Building and Environment, 2014. 71: p. 24-32.

[3] Al-Shareef, F.M., D.J. Oldham and D.J. Carter, A computer model for predicting the daylight performance of complex parallel shading systems. Building and Environment, 2001. 36(5): p. 605-618.

[4] Cheng, C., L. Liao and C. Chou, A study of summarized correlation with shading performance for horizontal shading devices in Taiwan. Solar Energy, 2013. 90: p. 1-16.

[5] Loutzenhiser, P.G., et al., An empirical validation of modeling solar gain through a glazing unit with external and internal shading screens. Applied Thermal Engineering, 2007. 27(2-3): p. 528-538.

[6] Loutzenhiser, P.G., G.M. Maxwell and H. Manz, An empirical validation of the daylighting algorithms and associated interactions in building energy simulation programs using various shading devices and windows. Energy, 2007. 32(10): p. 1855-1870.

[7] Guillemin, A. and S. Molteni, An energy-efficient controller for shading devices self-adapting to the user wishes. Building and Environment, 2002. 37(11): p. 1091-1097.

[8] Kim, J., et al., An experimental study on the environmental performance of the automated blind in summer. Building and Environment, 2009. 44(7): p. 1517-1527.

[9] Koo, S.Y., M.S. Yeo and K.W. Kim, Automated blind control to maximize the benefits of daylight in buildings. Building and Environment, 2010. 45(6): p. 1508-1520.

[10] Yao, J., A Multi-Objective (Energy, Economic and Environmental Performance) Life Cycle Analysis for Better Building Design. Sustainability, 2014. 6(2): p. 602-614.

[11] Crawley, D.B., et al., EnergyPlus: creating a new-generation building energy simulation program. Energy and Buildings, 2001. 33(4): p. 319-331. 